\title{
PERANCANGAN PUSAT BATIK PESISIR DENGAN PENDEKATAN ARSITEKTUR EKLEKTIK DI LASEM
}

\author{
Kunardi $^{1}$, Karya Widyawati ${ }^{2}$, Ukti Lutvaidah ${ }^{3}$ \\ ${ }^{1}$ Universitas Indraprasta PGRI, Program Studi Arsitektur \\ kunardi94@gmail.com \\ ${ }^{2}$ Universitas Indraprasta PGRI, Program Studi Arsitektur \\ karya.widyawati@unindra.ac.id \\ ${ }^{3}$ Universitas Indraprasta PGRI, Program Studi Arsitektur \\ Uktilutvaidah03@gmail.com
}

\begin{abstract}
Lasem is one of the centers of the coastal batik industry in the North Coast of Java Island, with the existence of the Perencanaan Pusat Batik Pesisir in Lasem its hoped that it will be able to accommodate batik trading activities for batik craftsmen in Lasem, becoming a place of learning for people as the successors of batik craftsmen, as well as a place of education and recreation for visitors. Aside from being the center of the batik industry, Lasem is also known as the city of Pecinan, to make the Pusat Batik Pesisir a landmark of Lasem, the concept taken in the design of this building is eclectic Architecture which is mixture of chinatown and modern styles.
\end{abstract}

Key Words: Center of Batik Pesisir, Eclectic Architecture, Lasem

\begin{abstract}
Abstrak : Kota Lasem merupakan salah satu pusat industri batik pesisir dengan wilayah strategis di Pantai Utara Pulau Jawa, dengan adanya Perencanaan Pusat Batik Pesisir di Lasem diharapkan akan dapat mewadahi aktivitas perdagangan batik bagi pengrajin batik di Lasem, menjadi tempat pembelajaran bagi generasi muda sebagai penerus pengrajin batik, serta menjadi tempat edukasi dan rekreasi bagi pengunjung. Selain sebagai pusat industri batik, Lasem juga dikenal dengan kota Pecinan, untuk menjadikan Pusat Batik Pesisir sebagai landmark kota Lasem, maka konsep yang diambil dalam perancangan bangunan ini adalah Arsitektur eklektik yaitu mencampurkan antara gaya Pecinan dan gaya Modern
\end{abstract}

Kata kunci : Pusat Batik Pesisir, Arsitektur Eklektik, Lasem

\section{PENDAHULUAN}

Batik merupakan hasil kebudayaan bangsa Indonesia yang patut dibanggakan. Pada tanggal 2 Oktober 2009 batik telah ditetapkan sebagai warisan budaya asli milik Indonesia oleh lembaga dunia UNESCO ( United Educational, Scientific, and Culture Organization ). Kain batik sangat kaya karena ragam hias batik terus berkembang dan berjalan seiring zaman sehingga menghasilkan ragam hias batik yang tidak terhitung jenisnya. Tidak hanya itu yang menjadikan batik istimewa, tetapi budaya dan tradisi yang ada di dalam diri batik juga yang harus dicermati.

Batik Pesisir adalah batik yang dibuat di luar Solo dan Yogyakarta. Istilah pesisir digunakan karena kebanyakan diproduksi di pesisir utara Jawa seperti di Cirebon, Indramayu, Lasem, Bakaran. Tak seperti batik kraton yang mewah namun banyak aturan, batik pesisir sifatnya komersil, lebih gaya, dan dipakai seharihari oleh rakyat dari segala kalangan, segala usia.
Variasinya lebih banyak dari segi warna maupun motif, hasil pengaruh asing yang dibawa para pedagang asing zaman dulu.

Dengan direncanakanya Pusat Batik Pesisir di Lasem diharap dapat memfasilitasi aktivitas perdagangan batik bagi pengrajin batik yang ada di Kota Pesisir Pantai Utara, dan juga meningkatkan sumber daya manusia masyarakat Lasem yang sebagian besar menjadi pengrajin batik, sehingga menambah pemasukan daerah kota Lasem di sektor perdagangan dan pariwisata. Dengan membawa gaya arsitektur eklektik yaitu antara gaya Modern dan Pecinan Lasem, Perencanaan Pusat batik Pesisir di Lasem diharap dapat menjadi icon Lasem yang mewujudkan citra batik Indonesia. 


\section{METODOLOGI}

\section{Metode Pendekatan Perancangan}

Dalam perancangan Pusat Batik Pesisir ini adalah dengan menggunakan Tema "Yin Yang dalam Arsitektur Modern".

Ajaran "Yin Yang" berasal dari filsafat Tionghoa dan metafisika kuno yang menjelaskan setiap benda di alam semesta memiliki polaritas abadi berupa dua kekuatan utama yang selalu berlawanan tapi selalu melengkapi. Yin bersifat pasif, sedih, gelap, feminin, responsif, dan dikaitkan dengan malam. Yang bersifat aktif, terang, maskulin, agresif, dan dikaitkan dengan siang. Yin disimbolkan dengan air, sedangkan Yang disimbolkan dengan api.

\section{Penerapan Prinsip Ying Yang dalam Arsitektur Modern}

Penerapan prinsip keseimbangan Yin Yang pada bangunan Phaeno Science Center di Wofsburg , Germany. Karya Zaha Hadid yang satu ini, teraplikasi pada penggunaan material yang saling berlawanan, antara yang solid dengan yang transparant, antara yang tegak dengan miring, antara yang memantulkan cahaya dengan yang menyerap cahaya. Selain itu pada bangunan Ordrupgaard Museum Extension, Copenhagen. Bangunan ini terletak di dalam site yang dikelilingi pepohonan, penataan pohon yang menutupi seluruh area site menambah kesan menyatu dengan alam. Pada Museum ini ditampilkan perpaduan penggunaan bahan yang kontras dengan lingkungan, seperti penggunaan kaca dan elemen struktur baja yang diekspose sehingga menampilkan suasana yang sangat kontras dengan lingkungan yang hijau. Penggunaan elemen-elemen kaca dan elemen logam sangat kontras dengan elemen alam seperti kayu dan pepohonan yang hijau. Tetapi disini sang arsitek berhasil membuat suatu "perbedaan" yang kontras tersebut menjadi sesuatu yang menyatu dan seimbang dengan alam.

\section{Metode Perencanaan Desain}

Metode perancangan yang digunakan dalam perancangan Pusat Batik Pesisir adalah dengan pendekatan Arsitektur Eklektik antara Pecinan dan Modern. Penggunaaan arsitektur pecinan dikareanakan lokasi banguanan ini berada di Lasem di mana tempat yang mempunyai peninggalan arsitektur pecinan lasem. Sedangkan untuk penggunaan arsitektur modern menyesuaikan gaya arsitektur kebanyakan di era saat ini.

\section{Aspek Ide/Gagasan}

Aspek ide merupakan tahap awal dalam metode apresiatif yang merupakan pemberangkatan ide awal dengan menggali potensi hingga menentukan gagasan awal. Ide/konsep Perancangan Pusat Batik Pesisir berawal dari penggalian potensi batik pesisir khususnya untk daerah Lasem sendiri yang membtuhkan wadah untuk memasarkan batiknya. Selain itu di Lasem sendiri mempunyai identitas Arsitektur Pecinan, yang mana gaya pecinan ini nantinya akan menjadi salah satu unsur gaya dari bangunan ini.

Eklektik antara Pecinan Lasem ini adalah memilih menggabungkan antara Gaya Pecinan dan Gaya modern, untuk gaya pecinan sendiri tetap mempertahankan bentukan atap yang khas dari arsitektur pecinan, selain itu organisasi ruang juga menggunakan analogi dari pecinan Lasem, dimana bagian depan adalah gerbang, taman (courtyard), teras depan, bangunan inti, hulung (tambahan yang berada disisi kiri kanan bangunan inti) ruang terbuka di belakang bangunan inti, dan pawon / dapur servis di bagian belakang. Sedangkan untuk gaya modern dominan diterapkan untuk bangunan Pusat Batik Pesisir ini dengan menggunakan bentuk yang minimalis, bentuk yang terbuka ( banyak elemen kaca).

\section{Aspek Transformasi}

Dalam tahap aspek transformasi merupakan tahap yang diawali dengan penggalian data terkait Pusat Batik Pesisir dengan pendekatan Arsitektr Eklektik. Penggalian data ini dilakukan dengan melakukan survey lapangan. Selain untuk penggalian data, survey lapangan juga dilakukan untuk penentuan lokasi tapak dan mengumpulkan data mengenai keadaan lingkungan dan potensi sekitar site atau lokasi terpilih. Dari data yang didapat, dilanjutkan dengan penentuan kriteria desain yang akan menjadi dasar analisa perencanaan dan perancangan, serta merumuskan konsep desain. Dalam tahap analisa dilakukan 
melalui proses penguraian data-data dan pembuatan gambaran sebagai media analisa. Tahapan analisa dikelompokkan menjadi analisa programatik dan analisa pemrograman arsitektur. Analisa programatik merupakan penerjemahan struktur pengguna dan kegiatan yang diwadahi. Analisa ini berkaitan dengan pendekatan sistem fungsi dari wadah arsitektur sehingga ditemukan persyaratan karakteristik respon desain. Sehingga dalam analisa ini dilakukan identifikasi pengguna dan alur kegiatan untuk mendapatkan konsep kegiatan dan ruang sesuai perencanaan Pusat Batik Pesisir di Lasem. Sedangkan analisa pemrograman arsitektur merupakan penerjemahan analisa berdasarkan fungsi dan persyaratan secara arsitektural ke dalam spesifikasi obyek yang dirancang. Dalam analisa ini dilakukan analisa program bentuk, ruang, tapak, struktur dan utilitas.

\section{Aspek Fisik}

Aspek fisik produk merupakan aspek dengan dua tahap akhir dari perencanaan dan perancangan, yaitu tahap sintesa dan apresiasi berdasar konsep. Tahap sintesa adalah penyatuan keseluruhan data dan hasil analisa untuk mencapai tujuan dan sasaran yang telah ditetapkan. Data dan analisa tersebut diolah dengan ketentuan dan persyaratan untuk menghasilkan olahan berupa konsep perencanaan dan perancangan antara lain konsep lokasi dan site, konsep peruangan, konsep tampilan bangunan, konsep utilitas dan struktur bangunan yang akan dikembangkan ditranformasikan dalam bentuk fisik.

\section{HASIL DAN PEMBAHASAN}

\section{Lokasi Proyek}

Tapak berada di Jl. Sultan Agung, Desa Gedungmulyo, Kecamatan Lasem, Kabupaten Rembang dengan luas lahan $+25.000 \mathrm{~m}^{2}$.

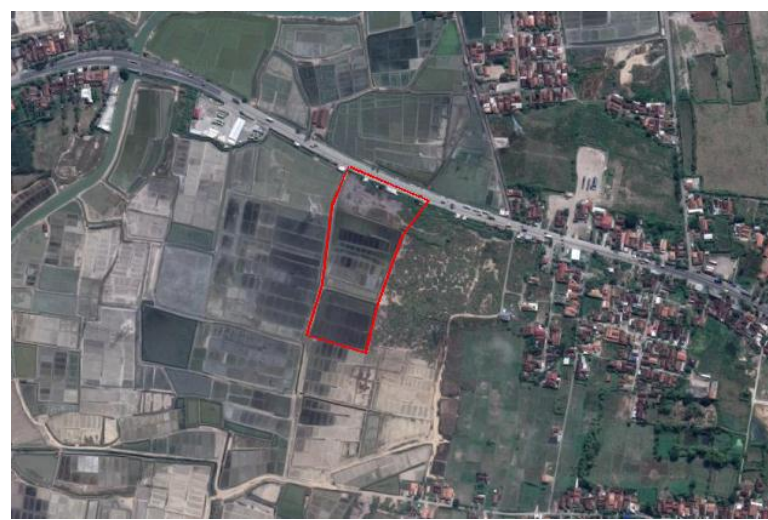

Gambar 1. Lokasi Tapak

1. Peruntukan : Industri besar

2. Luas Tapak : $25.000 \mathrm{~m}^{2}$

3. $\mathrm{KDB}: 60 \%$

4. KLB : 3.0

5. $\mathrm{KDH}: 2.5 \%$

\section{Analisa Tapak}

1. Batasan Site

Batasan tapak adalah sebagai berikut :

Sebelah Utara :Jalan raya dan lahan tambak garam

Sebelah Timur : Perumahan warga dan lahan tambak garam.

Sebelah Selatan: Lahan tambak garam dan lahan pertanian.

Sebelah Barat : Lahan tambak garam.

\section{Kondisi Eksisting Tapak}

Site terletak pada jalan utama arah Semarang Surabaya, kondisi tapak hampir cenderung pada tanah datar dengan sedikit tanaman/pepohohan. Terdapat tambak garam dan tanah kodong pada bagian kiri atau kanan Site.

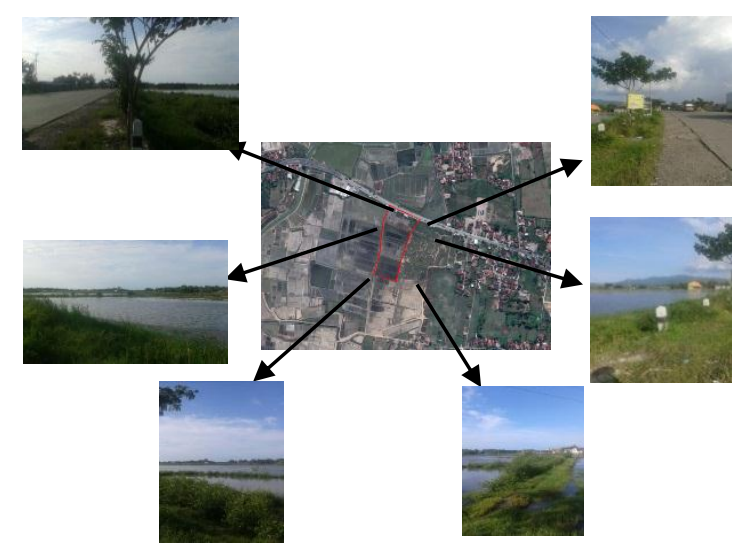

Gambar 2. Kondisi Eksisting Tapak 


\section{Konfigurasi Tapak}

Pada lokasi terpilih bentuk tapak sangat konteks, maka bentuk massa menyeseuaikan bentuk tapak. Bentuk yang di ambil adalah dari bentuk persegi panjang, dan sesuai dengan arsitektur pecinan bentuk bangunan menghadap ke utara selatan.

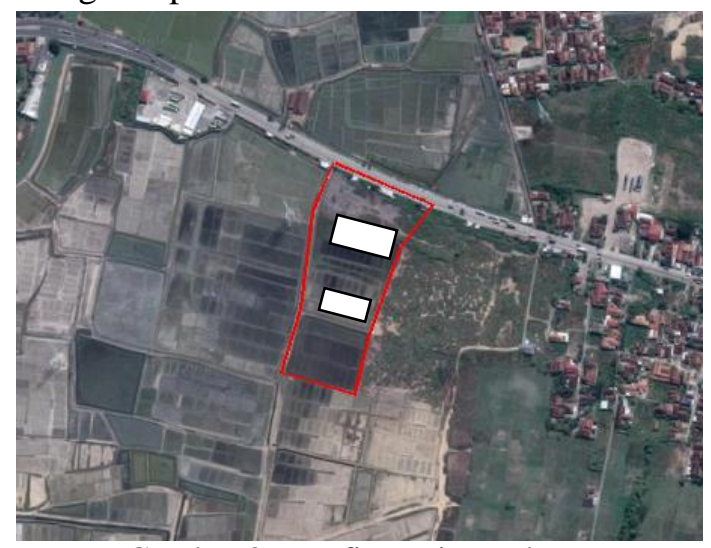

Gambar 3. Konfigurasi Tapak

\section{Pencapaian}

Kemudahan dalam pencapaian ke site ini adalah pencapaian darat yang satu-satunya transportasi sangat mudah dijangkau. Sistem transportasi ada dua yaitu, umum dan khusus. Transportasi umum merupakan pencapaian darat dengan menggunakan angkutan kota, ojek, dan bus. Sedangkan untuk yang khusus menggunakan kendaraan pribadi baik roda dua maupun roda empat.

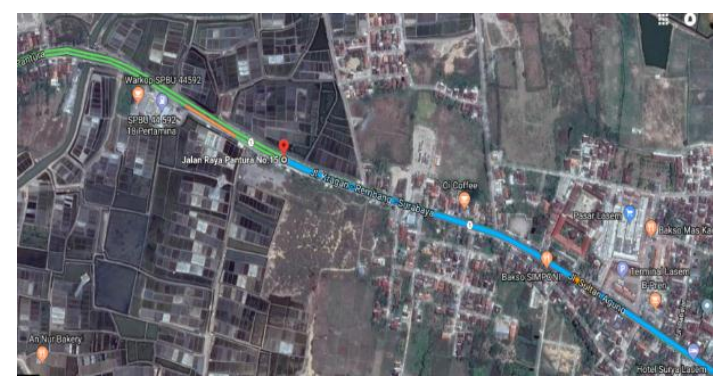

Gambar 4. Pencapaian Site

\section{Pencahayaan}

Sistem pencahayaan menggunakan pencahayaan alami dan buatan. Pencahayaan alami dimaksimalkan melalui bukaan-bukaan pada permukaan dinding yang lebar serta penggunaan material kaca sehingga cahaya matahari dapat masuk ke dalam ruangan. sistem pencahayaan alami digunakan hanya sebagai faktor pembentuk suasana ruang, digunakan padaruang-ruang pendukung kegiatan pameran, restoran, workshop, musholla.

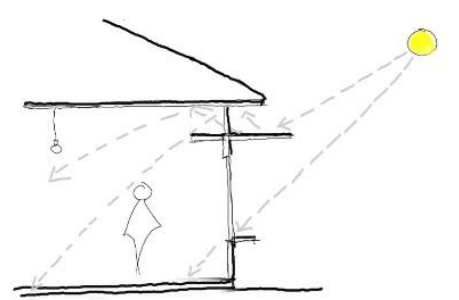

Gambar 5. Pencahayaan alami

Pencahayaan buatan digunakan sebagai faktor pendukung penampilan objek koleksi, pembentuk susasana ruang, mempertegas jalur pergerakan dan mengarahkannya, dan mengurangi kejenuhan selama pergerakan. pada Pusat Batik Pesisir menggunakan pencahayaan secara general lighting maupun accent lighting. General lighting diterapkan pada ruang-ruang yang komunal yang membutuhkan pencahayaan netral seperti lobby, lavatory, perpustakaan, dan penunjang lainnya. Accent lighting diterapkan pada ruang yang memiliki obyek khusus seperti ruang pamer dan galeri. Tipe accent lighting yang digunakan adalah wall-wash lighting, spotlighting, dan up-lighting. Spotlighting ini diterapkan pada obyek 3D maupun 2D. Sedangkan wall-wash lighting dan up-lighting digunakan pada aksen ruang.

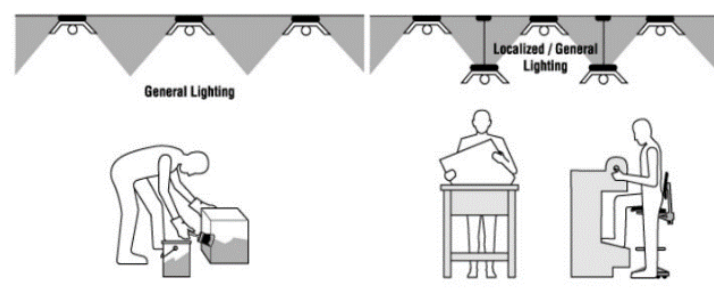

Gambar 6. Pencahayaan buatan

\section{Penghawaan}

Penanggulangan sistem penghawaan alami secara alamiah dilakukan dengan pengaturan layout dan konstruksi bangunan atas dasar sifat jalan dan arus udara melalui prinsip utama, yaitu udara mengalir dengan sendirinya dari bagian-bagian yang bertekanan tinggi kearah yang bertekanan rendah sebagai aplikasi aliran angin. Oleh 
karena itu diperlukan penempatan bukaanbukaan yang dapat mengoptimalkan pemakaian penghawaan alami.

Bangunan tidak bisa sepenuhnya bergantung pada udara alami. Selain jendela dan ventilasi, digunakan sistem tata udara pada bangunan, sehingga tercipta kenyamanan bagi penghuni, yaitu AC (Air Conditioning), yang berfungsi untuk mempertahankan suhu dan kelembaban dalam ruangan dengan cara menyerap panas dalam ruangan.

\section{Analisa Iklim}

Berdasarkan Climate Data, iklim di Rembang adalah tropis. Musim panas di sini memiliki curah hujan yang banyak, sedangkan musim dingin memiliki sangat sedikit. Klasifikasi iklim Köppen-Geiger adalah Aw. Suhu ratarata di Rembang adalah $25.7{ }^{\circ} \mathrm{C}$. Dalam setahun, curah hujan rata-rata adalah 1906 mm. Bulan terkering adalah Agustus. Di sana terdapat $22 \mathrm{~mm}$ presipitasi di Agustus. Hampir semua presipitasi di sini jatuh pada Januari, rata-rata $323 \mathrm{~mm}$. Dengan rata-rata $26.5{ }^{\circ} \mathrm{C}$, Oktober adalah bulan terhangat. Juli adalah bulan terdingin, dengan suhu rata-rata $25.0^{\circ} \mathrm{C}$. Presipitasi bervariasi $301 \mathrm{~mm}$ antara bulan terkering dan bulan terbasah. Sepanjang tahun, suhu bervariasi menurut $1.5^{\circ} \mathrm{C}$.

\section{Lahan Terbangun}

Luas lahan : $25.000 \mathrm{~m}^{2}(2.5 \mathrm{Ha})$

KDB $60 \%: 60 \% \times 25.000 \mathrm{~m}^{2}=15.000 \mathrm{~m}^{2}$

KLB $3: 3 \times 15.000 \mathrm{~m}^{2}=45.000 \mathrm{~m}^{2}$

Ketinggian maksimal $: \frac{45.000 \mathrm{~m}^{2}}{15.000 \mathrm{~m}^{2}}=3$ lantai

GSB : $: 4$ meter

\section{Penzoningan}

Analisis zoning dibuat dengan adanya parameter-parameter karakteristik kebutuhan ruang sebelumnya (view, pencahayaan, penghawaan dan ketenangan). hal ini sebagai sarana untuk mengelompokkan secara keseluruhan tiap-tiap ruang. pengelompokan tiap ruang dengan pembagian zona didasari dengan perbedaaan aktifitas dan kegiatan yang dilakukan oleh manusia itu sendiri, dimana pembagian zona ini berfungsi untuk tata letak bangunan, fungsi dan tatanan ruang luar.

Beberapa pembagian zona dalam perancangan Pusat Batik Pesisir adalah :

memberikan penaataan massa bangunan sesuai dengan aktivitas dalam ruang :

1. Zona Publik.

2. Zona Transisi.

3. Zona Semi Publik

4. Zona Privat.

5. Zona Servis.

6. Entance.

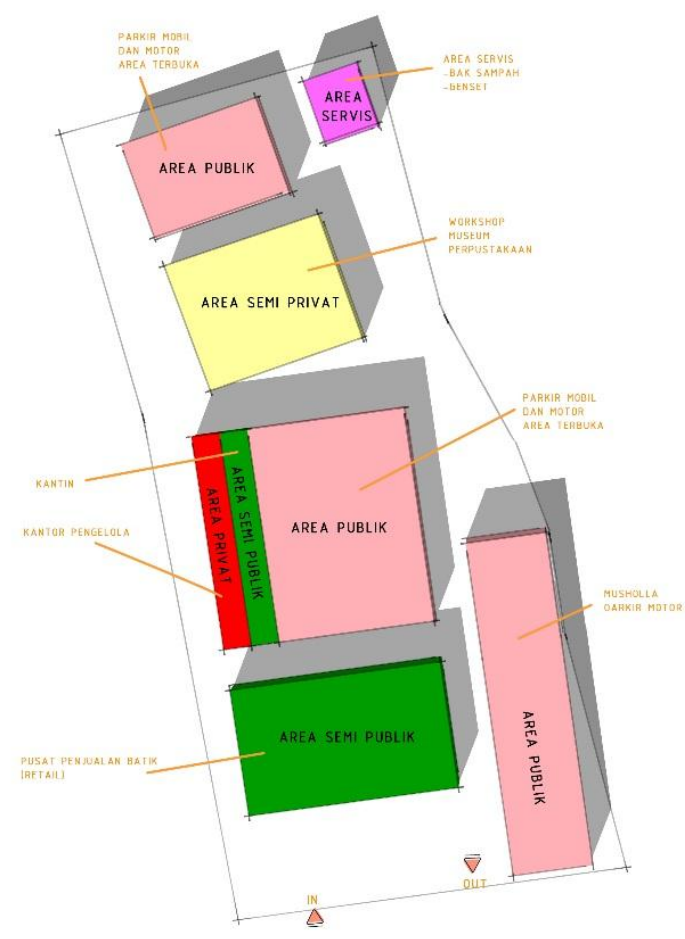

Gambar 7. Zoning Site

\section{Transformasi Bentuk}

Transformasi sebagai teknik permainan bentuk dengan memanipulasi bentuk Transformasi memiliki tujuan menghasilkan bentuk baru. Dengan permainan Bentuk secara terus menerus akan menghasilkan suatu komposisi bentuk yang mencerminkan pencitraan. (sutanto dan Surya,

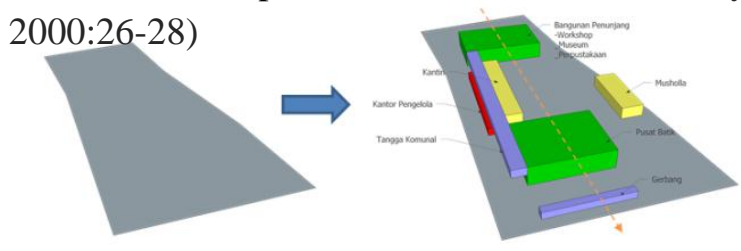

Gambar 8. Bentuk masa 
Bentuk dasar kotak memanjang di adopsi dari bentuk site terpilih. Disamping adopsi dari bentuk site, bentuk kotak juga menujukan kesan modern. Pembagian jumlah lantai sesuai kebutuhan. Serta permainan bentuk

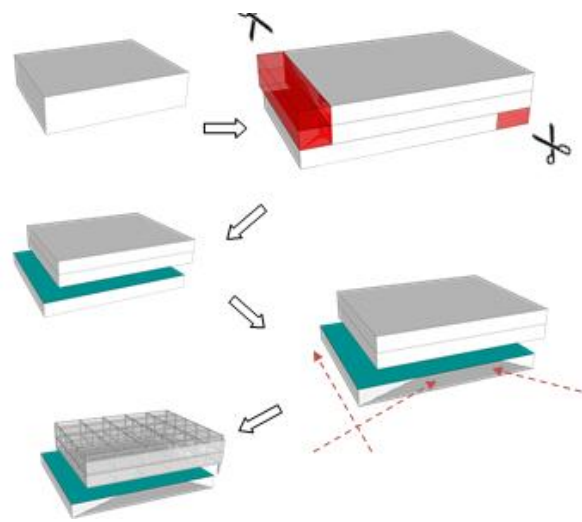

Gambar 9. Transformasi bentuk

(pengurangan masa) untuk menekan kesan modern. Penambahan kolam diatas untuk memasukan unsur air kedalam bangunan ini sesuai dengan unsur dalam tema Yin yang. penekanan Tema Yin-Yang dalam arsitektur modern ditekankan pada bangian ini. Dimana mengambil hal yang berlawanan yaitu penarikan antara garis tegak dan miring. Penambahan tangga akses kebangunan mengadopsi dari bangunan pecinan. struktur ekspos untuk meunjukan kekohan bangunan, seperti cirri khas bangunan pecinan lasem yang kokoh.

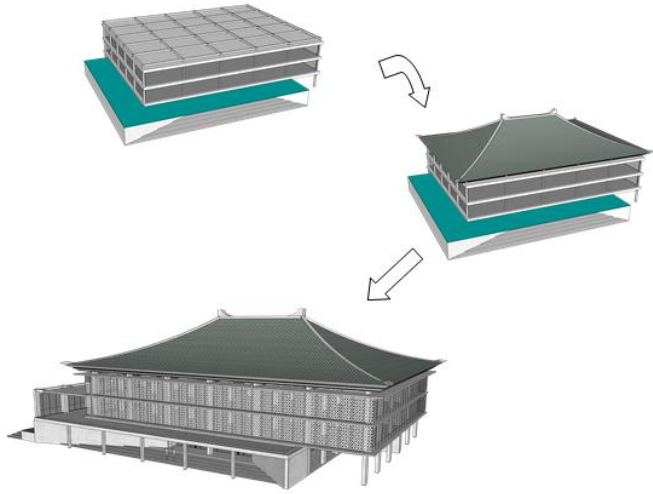

Gambar 10. Tranformasi bentuk

penggunaan material transparan untuk menunjukan kesan modern. Selain itu pengunaan bahan material transparent juga sesuai dengan pengunaan tema Yin Yang dalam arsitektur modern. Dimana penggunaan material yang berlawanan antara yang masiv dan transparan. bentuk atap mengadopsi langsung dari bangunan pecinan dimana mempunyai bentuk lengkung pada setiap jurainya.penggunaan secondary layer pada fasad ini berfungsi untuk meredam cahaya matahari yang masuk. Bentuk motif dari secondary layer ini merupakan adopsi dari motif batik.

\section{Desian}

\section{Perspektif \& Interior}

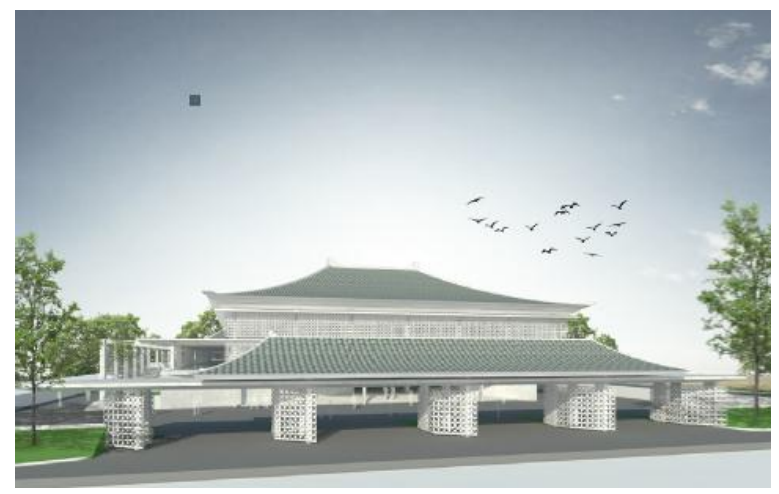

Gambar 11. Perspektif dari Jalan Raya

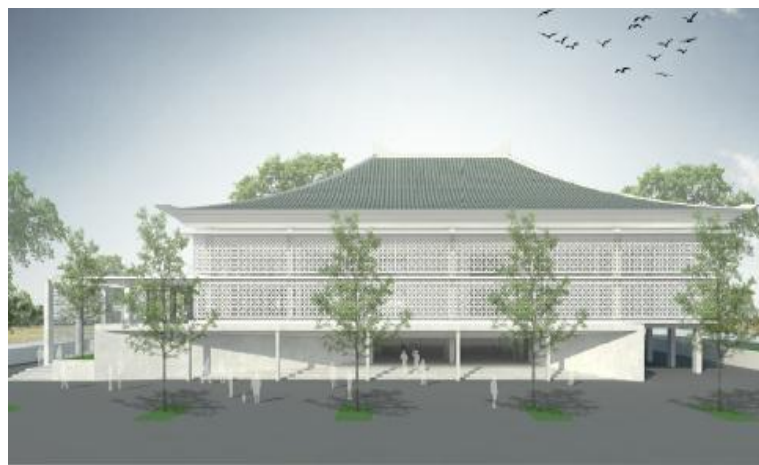

Gambar 12. Perspektif Pusat Batik

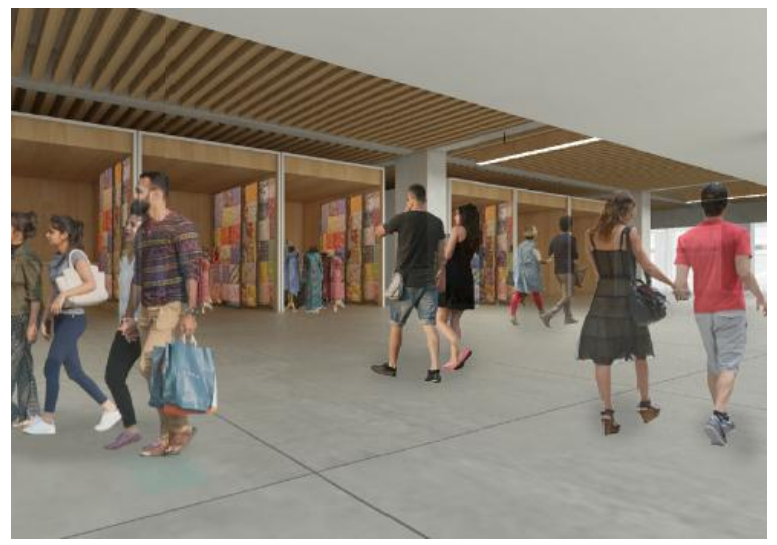

Gambar 13. Interior Pusat Batik 


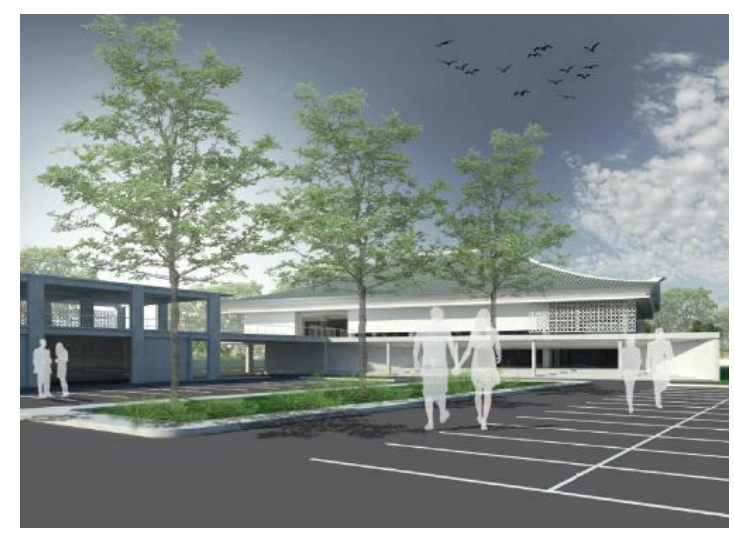

Gambar 14. Perspektif Museum - 1

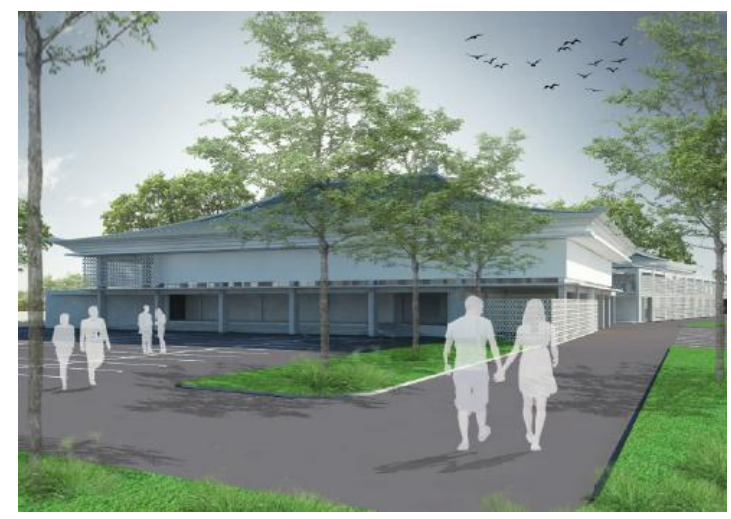

Gambar 15. Perspektif Museum - 2

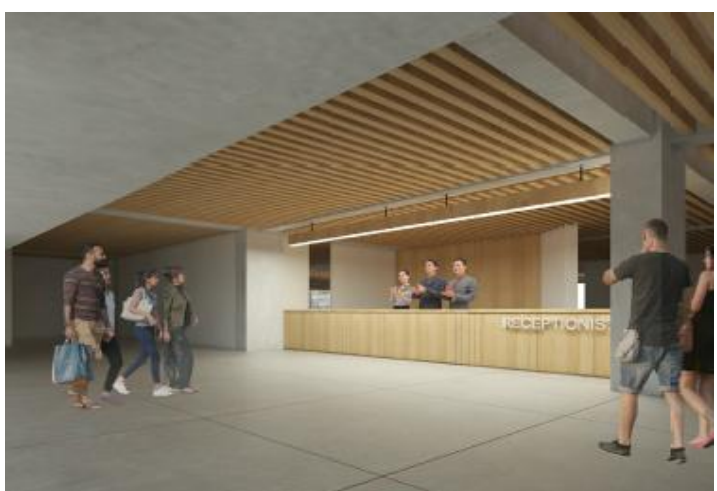

Gambar 16. Interior Museum

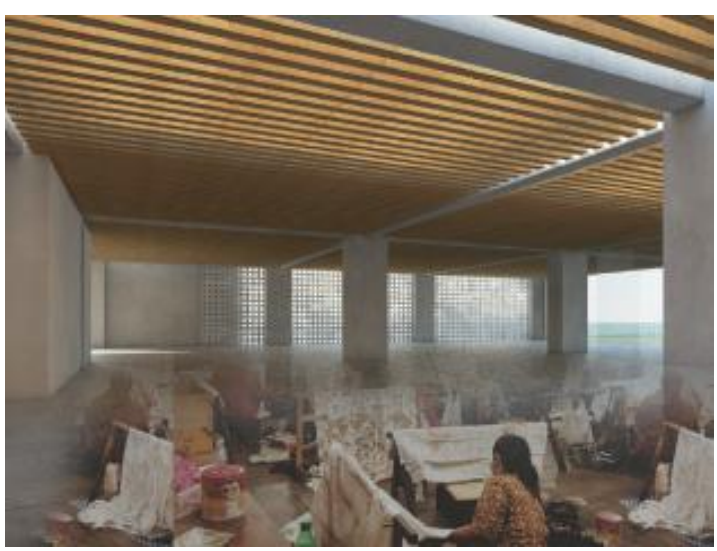

Gambar 17. Interior Wrokshop Batik

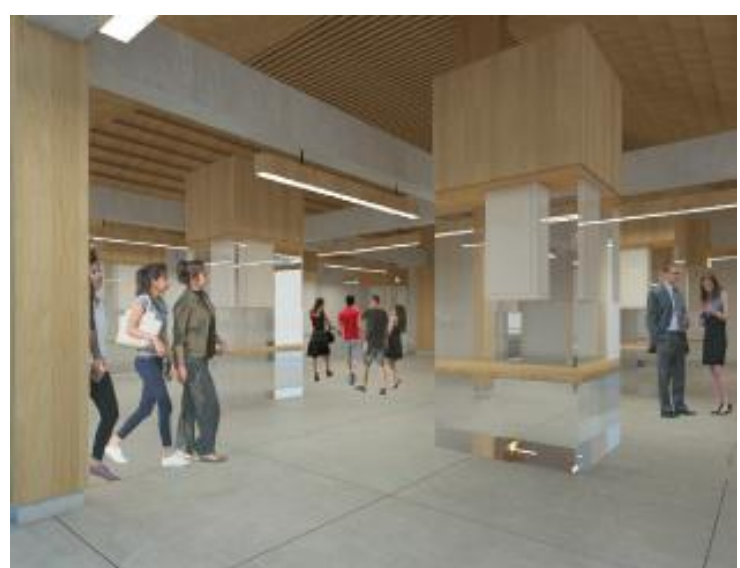

Gambar 18. Interior Ruang Pameran

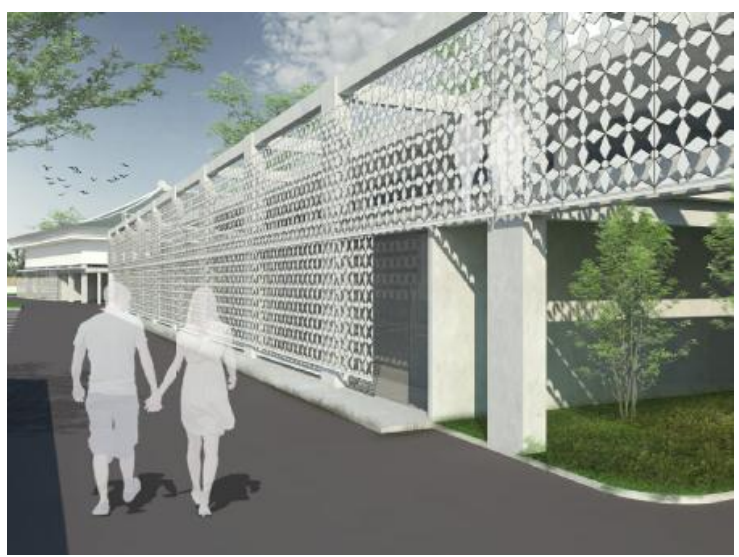

Gambar 19. Perspektif Kantor dan Kantin

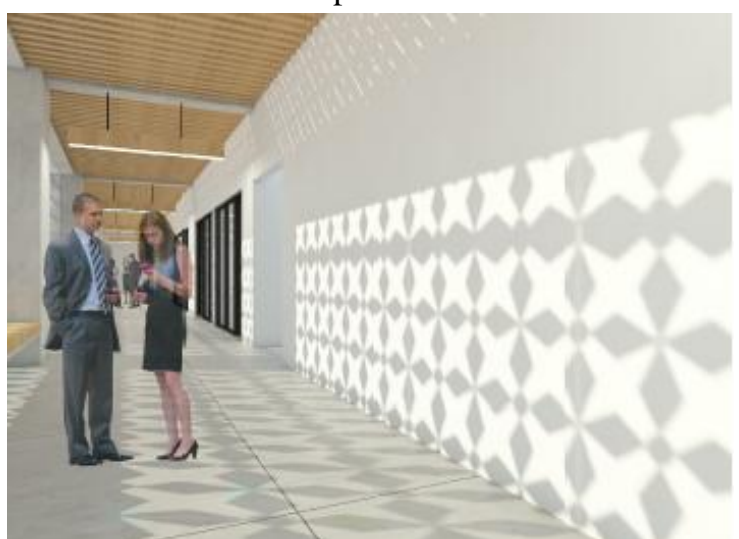

Gambar 20. Koridor Kantor

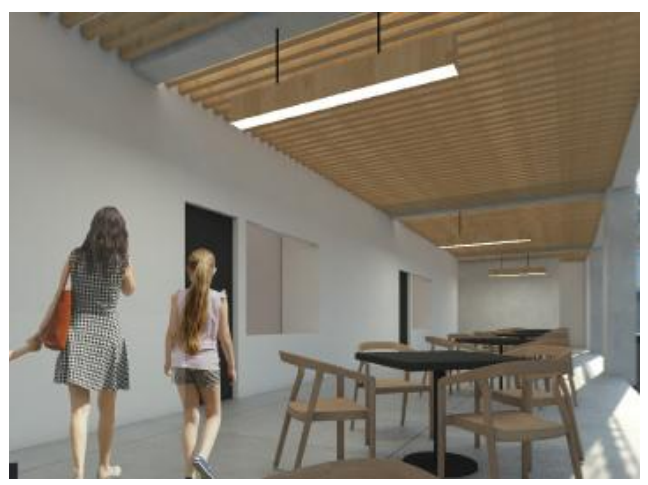

Gambar 21. Interior Kantor 


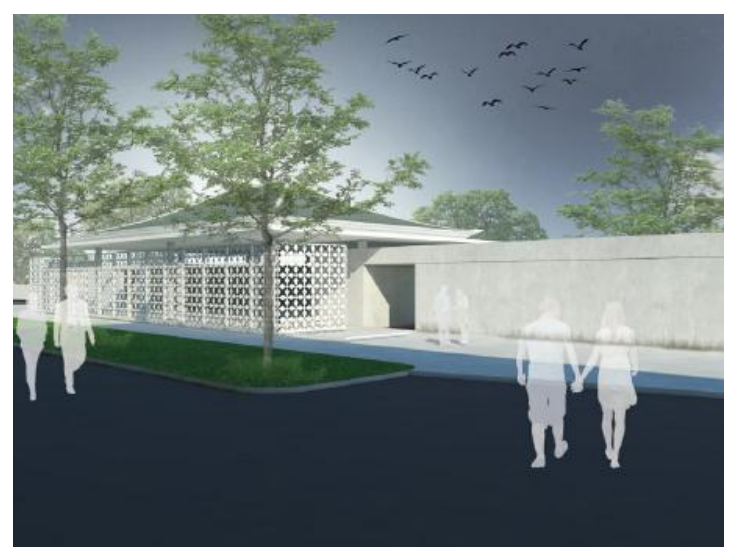

Gambar 22. Perspektif Musholla

\section{Denah}

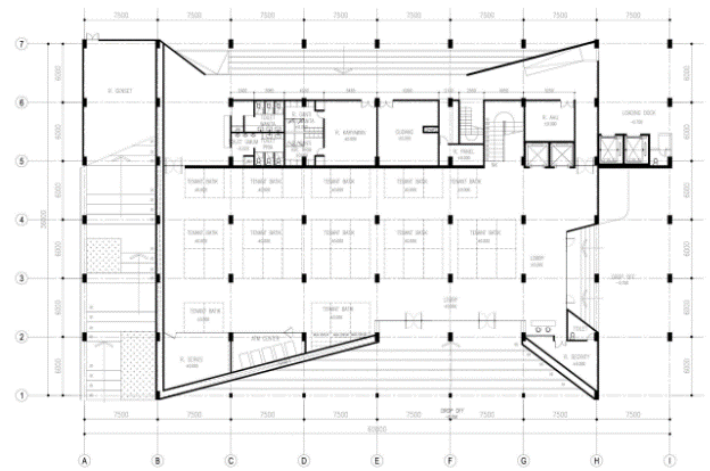

Gambar 24. Denah Pusat Batik Lantai 1

\section{Site Plan}

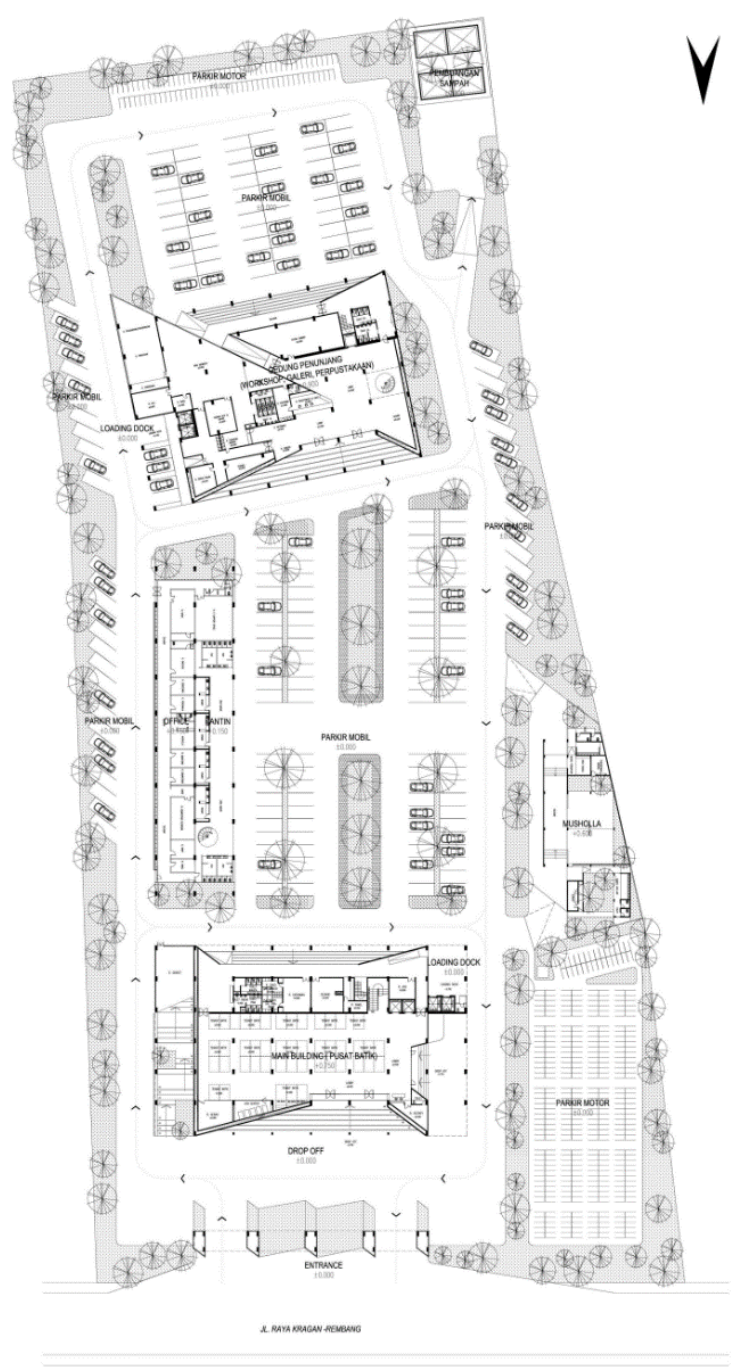

Gambar 23. Site Plan

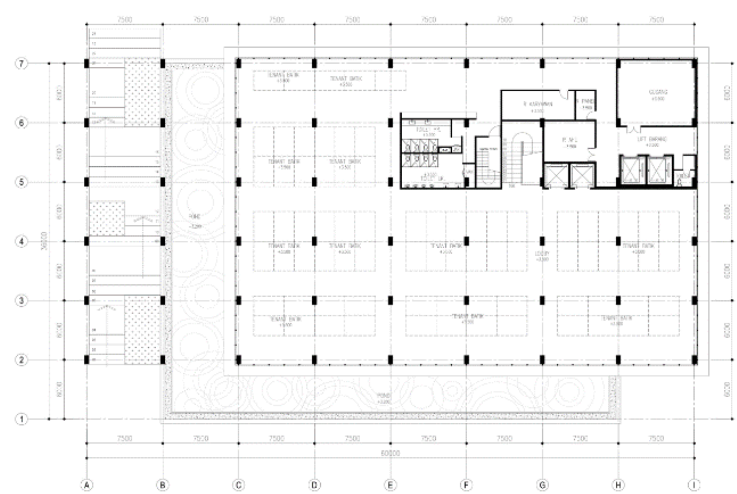

Gambar 25. Denah Pusat Batik Lantai 2

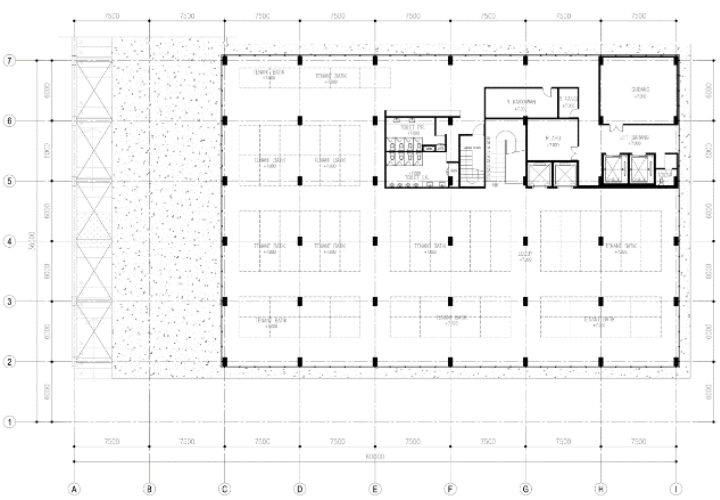

Gambar 26. Denah Pusat Batik Lantai 3

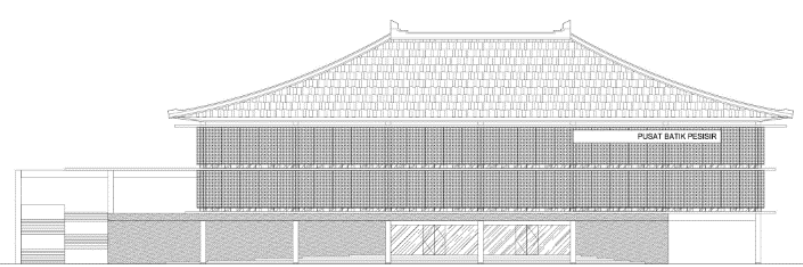

Gambar 27. Tampak Depan Pusat Batik 


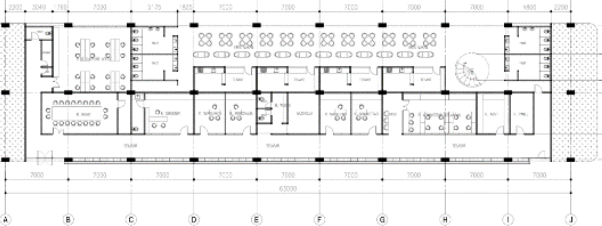

Gambar 28. Denah Lantai 1 Kantor \& Kantin

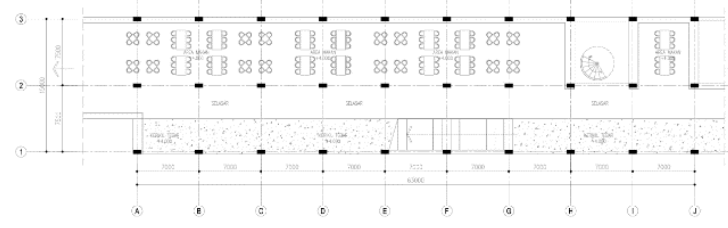

Gambar 29. Denah Lantai 2 Kantor \& Kantin

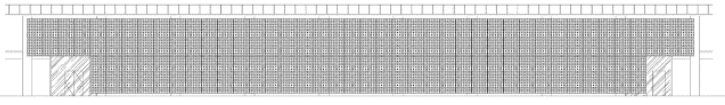

Gambar 30. Tampak Kantin \& Kantor

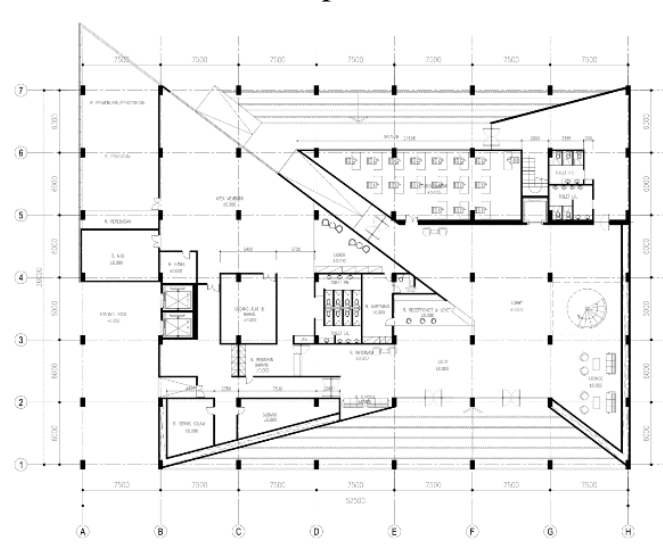

Gambar 31. Denah Lantai 1 Museum

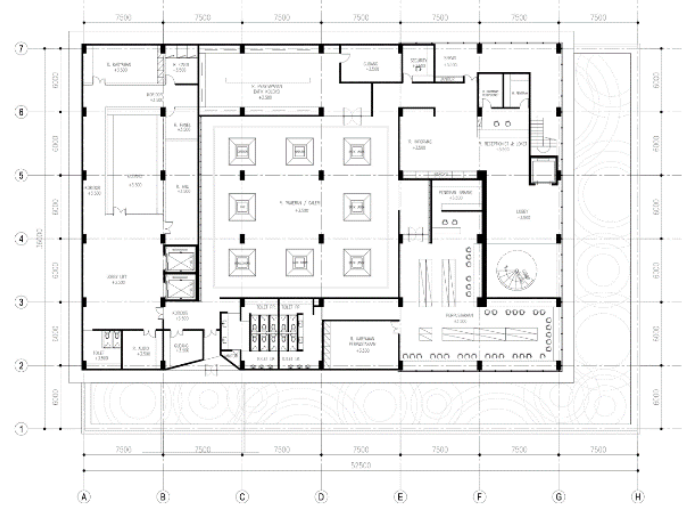

Gambar 32. Denah Lantai 2 Museum

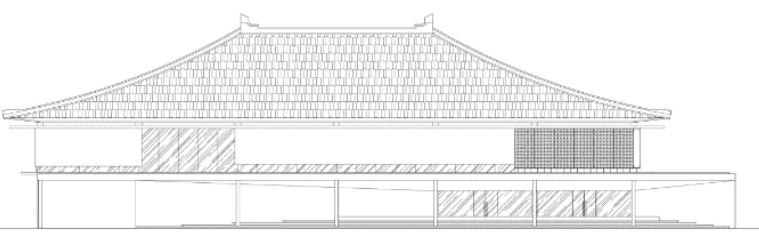

Gambar 33. Tampak Museum

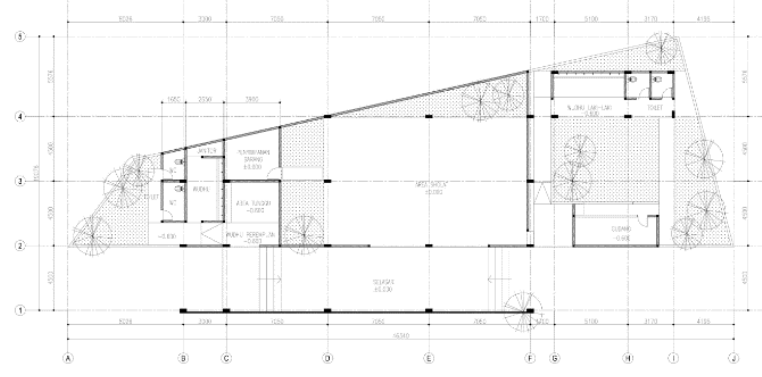

Gambar 34. Denah Musholla

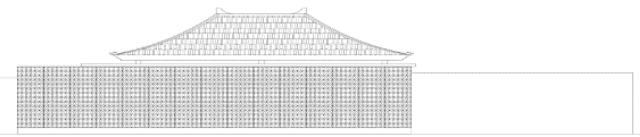

Gambar 35. Tampak Musholla

\section{PENUTUP}

\section{Simpulan}

Lasem merupakan salah satu daerah yang memproduki batik pesisir, namun kurangnya wadah untuk produksi maupun pemasaran batik tersebut, membuat pengrajin batik pesisir Lasem mulai berkurang, terutama untuk kalangan anak muda. Untuk dari itu Pusat Batik Pesisir diharapkan dapat menampung atau mewadahi kegiatan mulai dari pemasaran, dan edukasi tentang batik pesisir.

Bangunan Pusat Batik Pesisir ini merpakan bangunan dengan penerapan konsep eklektik antara modern dan pecinan. Mengusng gaya pecinan karena mengingat letak bangunan ini di daerah Lasem, dimana Lasem merupakan kawasan pecinan. Sedangkan untuk penggunaan gaya modern dikarenakan gaya ini merupakan gaya trend yang terjadi pada kebanyakan saat ini.

Penerapan konsep eklektik pada bangunan ini adalah memilih menggabungkan antara Gaya Pecinan dan Gaya modern, untuk gaya pecinan sendiri tetap mempertahankan bentukan atap yang 
khas dari arsitektur pecinan, selain itu organisasi ruang juga menggunakan analogi dari pecinan Lasem, dimana bagian depan adalah gerbang, taman (courtyard), teras depan, bangunan inti, hulung (tambahan yang berada disisi kiri kanan bangunan inti) ruang terbuka di belakang bangunan inti, dan pawon / dapur servis di bagian belakang. Sedangkan untuk gaya modern dominan diterapkan untuk bangunan Pusat Batik Pesisir ini dengan menggunakan bentuk yang minimalis, bentuk yang terbuka (banyak elemen kaca).

Transformasi bentuk menggunakan tema Yin Yang dalam arsitektur modern, dimana penerapan yang dipilih adalah penggunaan material yang saling berlawanan, antara yang solid dengan yang transparant, antara yang tegak dengan miring, dan antara yang memantulkan cahaya dengan yang menyerap cahaya.

\section{Saran}

Senantiasa melakukan studi literatur baik secara tekstual maupun konstekstual yang cukup agar hasil yang didapatkan mempunyai tingkat kajian yang dalam.

\section{DAFTAR PUSTAKA}

Buku

D. K. Ching, Francis. 2008. Arsitektur, Bentuk, Ruang dan Susunannya. ed.ke-3. Terj. Hanggan Situmorang. Jakarta: Erlangga.

Sumaryoto. 2015. Pedoman Penulisan

Skripsi/Tugas Akhir. Jakarta: Universitas Indraprasta PGRI.

\section{Jurnal}

Herwandana, Dewa Gede Satria. 2017. "YinYang dalam Arsitektur Modern".

Zahnd, Markus. 2009. Pendekatan dalam

Perancangan Arsitektur. Yogyakarta: Kanisius.

\section{Website}

Adi, Wendi Mustika. 2011. "Beberapa Ciri dari Arsitektur Tionghoa di daerah Pecinan sampai sebelum tahun 1900" di http://campuradukgadogado.blogspot.com

Pratama, Agung. 2015. "Sejarah Perkembangan Arsitektur II, Arsitektur Eklektik", di https://www.scribd.com, di akses pada Mei 2018. 